\title{
Uma Abordagem ao Desenvolvimento Local Inspirada em Celso Furtado e Milton Santos
}

Sueli Goulart ${ }^{1}$

\begin{abstract}
Resumo
Parcerias, consórcios, arranjos produtivos locais, redes e outras variações interorganizacionais vêm sendo formuladas, estudadas e avaliadas como configurações capazes de promover o desenvolvimento de localidades, em diferentes escalas. Sob diferentes abordagens teóricas e nas variadas áreas da Administração, essas formas são entendidas, via de regra, como adequadas para fomentar o desenvolvimento no contexto do mundo globalizado. Entretanto, com exceções, 0 desenvolvimento local tem sido tomado como resultado natural e automático daquelas iniciativas ou dos novos arranjos institucionais movidos por elas. Este artigo explora elementos teórico-empíricos formulados por Celso Furtado e Milton Santos para buscar uma alternativa de entendimento e de conteúdo praxiológico ao construto desenvolvimento local. Para substanciar as reflexões, apresenta parte de um trabalho empírico referente à formação do pólo de tecnologia de informação e comunicação de Pernambuco. Finaliza com as inquietações e as implicações para os estudos organizacionais, resultantes da inspiração buscada naqueles autores.
\end{abstract}

Palavras-chave: Desenvolvimento territorial; Arranjo produtivo local; Subdesenvolvimento; Redes interorganizacionais

\begin{abstract}
Partnerships, trusts, local productive arrangements, interorganizational networks and other variations have been formulated, studied and evaluated as configurations capable to promote the development of localities, in different scales. Under different theoretical approaches and in the varied areas of the Administration, these forms are understood, usually, as adjusted to foment the development in the context of the globalization. However, with exceptions, the local development has been taken for granted as natural and automatic resulted of those initiatives or the new institucional arrangements moved by them. This article explores elements theoretician-empiricists formulated by Celso Furtado and Milton Santos to search an alternative of agreement and praxiological content to the concept of local development. To substantiate the reflections, it presents part of a referring empirical work to the formation of the local productive arrangement of information technology and communication of Pernambuco. It finishes with the fidgets and the implications for the organizational studies, resultants of the inspiration searched in those authors.
\end{abstract}

Keywords: Territorial development; Local productive arrangement; Underdevelopment; Interorganizational networks

\section{Introdução}

Parcerias, consórcios, arranjos produtivos locais, redes e outras variações interorganizacionais vêm sendo formuladas, estudadas e avaliadas como configurações capazes de promover o desenvolvimento de localidades, em diferentes escalas: comunidades, cidades, regiões, estados, países. Sob diferentes abordagens teóricas e nas variadas áreas da Administração, essas formas são entendidas, via de regra, como adequadas para fomentar o desenvolvimento no contexto do mundo globalizado. Ou porque desoneram o Estado do papel de principal indutor do desenvolvimento, imperativo para o livre funcionamento das leis de mercado na economia-mundo; ou porque garantem sobrevivência e competitividade, particularmente às pequenas e médias empresas; ou porque resgatam vocações e identidades locais; ou porque comportam a articulação de diferentes atores,

\footnotetext{
1 Doutora em Administração pela Universidade Federal de Pernambuco. Bibliotecária da Universidade Federal de Alagoas. Endereço: Campus A. C. Simões, BR 104 - Norte, Km 97, Cidade Universitária - Maceió - AL - CEP 57072-970. E-mail: sueligoulart@ uol.com.br.
} 
abrindo espaço para a participação da sociedade civil em decisões de investimentos governamentais e/ou na elaboração de políticas públicas; ou ainda porque se constituem em espaços profícuos para inovações, igualmente valorizados como diferencial competitivo, dentre tantos outros argumentos.

Em geral, os governos, nas escalas municipal ou estadual, as organizações não-governamentais (ONGs) ou as agências de serviços especializados, como o SEBRAE, por exemplo, são identificados como protagonistas nas iniciativas de criação de tais formas interorganizacionais. Criação de emprego e renda, fortalecimento dos laços de solidariedade e construção de matrizes institucionais confiáveis são, igualmente, apontadas como resultantes de tais iniciativas e propulsoras de patamares mais elevados de desenvolvimento.

É certo que o crescente interesse dos pesquisadores da área de Administração pela temática do desenvolvimento contribui para ampliar as discussões a respeito das relações organização e ambiente, dos efeitos concretos das ações organizacionais no mundo da vida e, em última análise, das relações entre teoria e prática. Entretanto, com as exceções que se destacam, entre outras razões, por buscarem articulações com outras disciplinas e construtos, por serem conduzidas por grupos interdisciplinares e se desenvolverem ao abrigo de programas de longo prazo ${ }^{1}$, o desenvolvimento local tem sido tomado como resultado natural e automático daquelas iniciativas ou dos novos arranjos institucionais movidos por elas. Ou seja, há uma parcela significativa de trabalhos que exploram as formas, os arranjos, o impacto econômico de atividades específicas, os fatores de sucesso e fracasso na formatação de redes, mas muito pouco se diz sobre a ocorrência, ou não, de transformações sociais no espaço territorial em que se desenrolam tais fenômenos organizacionais.

Essa situação limita o entendimento das implicações das ações organizacionais na sociedade, pois as análises terminam se confinando ao ambiente das organizações, constituído por outras organizações, supostamente direcionadas a um objetivo comum. Oferece ainda o risco de se verem confundidos papéis e lógicas dos diferentes agentes individuais e coletivos que constituem tais redes, negligenciando relações de poder que ali ocorrem e, conseqüentemente, naturalizando a reprodução de modelos hegemônicos.

Provocado pela temática central do IV Encontro de Estudos Organizacionais (IV ENEO) que, em linhas gerais, incita a "honrar nossa tradição intelectual e abordar temas relevantes", este artigo explora elementos teóricoempíricos formulados por dois importantes intelectuais brasileiros - Celso Furtado e Milton Santos - para buscar uma alternativa de entendimento e de conteúdo praxiológico ao construto desenvolvimento local, posicionado no contexto da globalização. Após a apresentação e discussão de tais elementos, é apresentada parte de um trabalho empírico realizado no campo dos estudos organizacionais, mais para substanciar as reflexões do que para mostrar uma aplicação do referencial discutido. Ao final, tece considerações a respeito das implicações da abordagem apresentada percebidas até aqui, já que este é um trabalho em construção, fruto de inquietações geradas pela aproximação à obra dos autores referidos contraposta ao que se observou no trabalho empírico e também às abordagens frequientemente encontradas nos estudos organizacionais, com as exceções referidas.

\section{Para posicionar a abordagem: revisitando Celso Furtado e Milton Santos}

Os estudos sobre desenvolvimento tiveram lugar central na agenda de cientistas sociais latino-americanos especialmente desde o final da Segunda Guerra Mundial até meados da década de 70, orientados por duas principais correntes de pensamento: a liberal e a estruturalista. A primeira, defensora do mercado como mecanismo regulador por excelência e do individualismo como motor da ação social, assumia a sinonímia entre crescimento econômico e desenvolvimento, cujo caráter evolutivo recomendava, em termos gerais, copiar modelos e experiências dos chamados países desenvolvidos para que essa condição fosse atingida pelos demais. A corrente histórico-estruturalista, nos trabalhos da Comissão Econômica para a América Latina e o Caribe (CEPAL) e de seus intelectuais, como Raúl Prebisch e Celso Furtado, questionava aquela lógica, especialmente mediante a formulação de categorias teórico-empíricas como a dicotomia centro-periferia na estruturação do sistema econômico mundial e as características intrínsecas e particulares do subdesenvolvimento. 
Apesar do vigor e da originalidade do pensamento cepalino, é certo que as idéias defendidas por seus intelectuais foram suplantadas pela corrente liberal, em consonância com a onda ditatorial que varreu o continente sul-americano entre as décadas de 60 e 80. É certo também que, no caso do Brasil, o desenvolvimento econômico alcançou seus melhores índices de crescimento justamente no início da década de 70, auge do período dos governos militares que se seguiram de 1964 a 1984. Entretanto, a repercussão na estrutura social brasileira se deu na forma de uma acelerada "modernização dos padrões de consumo" e não de uma efetiva transformação, nos termos propostos por Furtado (2000a, p. 27).

A débâcle mundial da década de 70, particularmente movida pelas crises do petróleo de 1973 e 1979, levou à erosão e ao colapso dos sistemas sobre os quais repousaram as discussões anteriores. Dessa forma, os modelos de desenvolvimento, fossem os de orientação liberal, fossem os de orientação keynesiana, foram postos em xeque.

Ameaças de esgotamento dos recursos naturais, crises do petróleo e da dívida externa, disseminação das novas tecnologias de informação e comunicação, reestruturação produtiva e o fim dos embates entre os dois grandes sistemas políticos mundiais, contribuíram para submergir as preocupações com o desenvolvimento numa agenda pública dominada por situações críticas (SUNKEL, 2001). Sua re-emergência ocorre, então, sob outro enfoque que, a despeito da inclusão de novos e abrangentes temas, se retrai para abordagens tendencialmente micro-analíticas, de orientação neoliberal.

Vindo de se constituir desde a emergência dos movimentos culturais ocorridos nos anos 60, o movimento ambientalista ampliou, durante a década de 70, seus questionamentos para além dos recursos naturais, passando a abranger questionamentos relativos à superpopulação, aos custos da tecnologia e do crescimento econômico.

Seguidos estudos, entre eles aquele realizado pelo Clube de Roma, em 1972, intitulado "Os Limites do Crescimento", e debates como o ocorrido durante os preparativos que antecederam a Conferência das Nações Unidas, também realizada naquele ano, opunham partidários do que Sachs (2000, p. 52) denominou de "economismo arrogante" e "fundamentalismo ecológico". Para os primeiros, a aceleração do desenvolvimento industrial dos países periféricos lhes permitiria alcançar o padrão dos países centrais e previa que a equiparação da renda per capita dos países neutralizaria as externalidades negativas; os últimos previam a exaustão dos recursos e o agravamento dos efeitos da poluição e a necessidade imperiosa de estagnação do consumo. Ou seja, a linearidade do radicalismo econômico era confrontada pelo irrealismo do crescimento zero.

Sob forte influência da ideologia neoliberal que, em fins da década de 70, assumiu o comando em duas das maiores potências mundiais com a eleição de Margareth Tatcher na Inglaterra e de Ronald Reagan nos Estados Unidos, aprofunda-se o processo de globalização. Porque imbricado ao fortalecimento da ideologia neoliberal esse processo contribuiu para a proeminência do espaço econômico e financeiro sobre os demais espaços social, cultural, político (VIEIRA e VIEIRA, 2003).

$\mathrm{Na}$ esteira do movimento ecológico e da busca por modelos alternativos, a Organização das Nações Unidas (ONU) articula a formação da Comissão Mundial sobre Meio Ambiente e Desenvolvimento composta, em sua maioria, por representantes de países em desenvolvimento e de ONGs ambientalistas. Dentre os resultados dos trabalhos dessa Comissão está a publicação do Relatório Brundtland, em 1988, que formalizou o conceito de desenvolvimento sustentável: “... aquele que atende as necessidades do presente sem comprometer a possibilidade das gerações futuras atenderem suas próprias necessidades" (BRUNDTLAND, 1991, p. 46). Sob o manto da preservação do meio ambiente, manteve-se a ênfase econômica, uma vez que a deterioração ambiental é tomada em seu potencial de impedir ou reverter o crescimento econômico.

O Relatório Brundtland tornou-se referência não apenas para a maioria dos estudos sobre desenvolvimento sustentável, mas também para o direcionamento de ações estratégicas alternativas no contexto das políticas públicas. Legitimado como discurso de relevante questão de interesse internacional, o Relatório atribuiu diferentes papéis aos países: aos em desenvolvimento caberia a preservação do ambiente ecológico, deteriorado em função de seus problemas sociais e de sua incapacidade administrativa e financeira; aos desenvolvidos, a oferta de alternativas tecnológicas e financeiras para viabilizar novos padrões de desenvolvimento (OLIVO e 
MISOZKY, 2003). A âncora financeira seriam os programas de agências internacionais, notadamente o Banco Mundial.

Mas, Ignacy Sachs, um dos principais teóricos contemporâneos da sustentabilidade, assegura que as características desse "outro desenvolvimento" são: a endogenia, a auto-suficiência, a orientação para as necessidades e não para o incentivo ao consumo, a harmonia com os recursos naturais e a implementação de mudanças institucionais (SACHS, 2000, p. 52).

Somado às discussões teóricas emergentes, a localidade passou a constar da agenda de pesquisadores, de formuladores de políticas e dos governantes brasileiros a partir do início dos anos 90, também em decorrência do novo desenho institucional proposto pela Constituição brasileira de 1988 e o processo de descentralização das políticas públicas.

Goulart, Vieira e Carvalho (2005) lembram, entretanto, que a endogenia e a auto-suficiência não podem mascarar a natureza macro-estrutural do desenvolvimento, particularmente em face da permeabilidade do processo de globalização vigente no mundo contemporâneo. Ou, como afirma Brandão (2000, apud TENÓRIO, DUTRA e MAGALHÃES, 2004, p. 11) "é preciso ter clareza que apenas o ser hegemônico detém real poder de iniciativa, de 'endogenia de desenvolvimento', de regulação e de administração dos limites e possibilidades para si e dos outros".

Na localidade definem-se espaços de articulação e implementação das ações voltadas para o desenvolvimento mas, como se verá mais adiante, os lugares tornaram-se alvo de competição e recursos disputados por agentes externos, cujo poder de pressão é tanto maior quanto forem o domínio tecnológico e a capacidade de articulação político-econômica que detêm.

Assim, a noção e as estratégias de desenvolvimento se assentam em diferentes lógicas e interesses que conformam uma rede de relações determinantes na conformação dos lugares, de orientação global ou local. Santos (2002b, p. 96) fala em lógicas exógena e endógena; a primeira situada no âmbito dos interesses corporativos globais, transnacionais e a última no âmbito da identidade, do fato e do sentimento "de pertencer àquilo que nos pertence".

Sob a primeira, definem-se estratégias funcionais ao capitalismo global (FURTADO, 2000a), transformando economias nacionais, especialmente a dos países em desenvolvimento, em províncias da economia global (IANNI, 2002), numa clara exacerbação da dimensão econômica e instrumental da noção de desenvolvimento. Sob a última, constroem-se políticas que resgatam especificidades e expandem a noção de desenvolvimento para a dimensão cultural, isto é, para "os valores das coletividades, os sistemas simbólicos que constituem a cultura" (FURTADO, 2000a, p. 70).

No contexto geopolítico, essas diferentes lógicas caracterizam os lugares-locais e os lugares-globais. Os primeiros delimitam o espaço da herança histórica que, mesmo reestruturado em função de estratégias globais, mantêm uma identidade. São ainda a base da organização territorial e das relações de produção. Ainda que extrapolem limites geográficos, se assentam em especificidades sócio-culturais, políticas e institucionais particulares a um grupamento humano, com identidade própria. Os lugares-globais são espaços definidos por conseqüência da globalização neoliberal, fundamentalmente separando o centro da ação da sede da ação. São "o espaço para as estratégias mundiais das grandes corporações multinacionais, estabelecendo redefinições territoriais e mudanças nos procedimentos de gestão" (VIEIRA e VIEIRA, 2003, p. 20).

Sob lógica exógena, o crescimento econômico é tomado como determinante do desenvolvimento e justifica, por exemplo, a guerra fiscal entre os estados brasileiros, em anos recentes. Sob uma argumentação pseudo-localista, políticas governamentais cedem parcela significativa de seus orçamentos aos interesses de grandes empresas; estas, no dizer de Santos (2002a), transformam o chão, por meio da técnica e das decisões políticas que determinam, em fonte de mais-valia. Assim, "a produtividade e a competitividade (...) passa, também, a ser um atributo dos lugares. E cada lugar entra na contabilidade das empresas com diferente valor. A guerra fiscal é, na 
verdade, uma guerra global entre lugares" (SANTOS, 2002a, p. 88). Uma guerra que, sob o manto da articulação empresas - Estado, antecipa a vitória àqueles que determinam sua lógica.

Furtado (1974, p. 68-69), ao tratar do que considerou "o mito do desenvolvimento econômico", já alertava que, no quadro estrutural do sistema capitalista, o processo de acumulação, orientado pelas grandes empresas, "tende a ampliar o fosso entre um centro, em crescente homogeneização, e uma constelação de economias periféricas, cujas disparidades continuam a [se] agravar".

Trinta anos depois dessa afirmação, dados divulgados pelo jornal Folha de São Paulo, baseados em estudos da ONU, mostram que a globalização aumentou a diferença entre países ricos e pobres: "no começo dos anos 60, a renda per capita nas nações mais pobres era de US\$212, enquanto nos países ricos era de US\$ 11.417; em 2002, essas cifras passaram a US\$ 267 (+26\%) e US\$ 32.339 (+183,3\%), respectivamente" (GLOBALIZAÇÃO..., 2004, p. B1).

Vê-se, portanto, que a categorização do espaço geográfico em lugares-globais e lugares-locais corresponde, não por coincidência, à estrutura centro-periferia, já discutida desde os anos 60. Naquela época, essa estrutura indicava basicamente a diferença entre países industrializados e países não-industrializados. Agora, a dicotomia é reproduzida, praticamente com os mesmos atores, diferenciando países geradores de conhecimento, tecnologia e inovação e aqueles que são meros reprodutores ou operadores das estruturas definidas no centro do sistema econômico mundial. Àquela época essa estrutura garantiu a hegemonia dos países centrais numa divisão internacional do trabalho que restringiu o processo de industrialização dos países periféricos à "modernização dos padrões de consumo" (FURTADO, 2000a, p. 27). Agora pretende definir as condições de sua inserção no processo de globalização, ora como fornecedor de mão-de-obra ou infra-estrutura espacial e fiscal de baixo custo, ora como espaço de especulação financeira.

A estrutura centro-periferia apresentada por Raúl Prebisch no final da década de 40 e a teoria da dependência elaborada por Fernando Henrique Cardoso e Enzo Falleto são reconhecidas por Furtado (2000a) como base para a formulação da teoria do subdesenvolvimento. A partir daquelas bases foi possível caracterizar o processo desenvolvimento-subdesenvolvimento como expressões de estruturas sociais. Ao primeiro, corresponde uma efetiva transformação das estruturas sociais; o último se restringe à modernização do estilo de vida. Assim, o subdesenvolvimento pôde ser especificamente caracterizado "como a conformação de sociedades em que relações externas assimétricas, que geram dependência, articulam-se internamente com o sistema de dominação social" (FURTADO, 2000a, p. 39).

Por isso, essas mesmas categorias continuam a fazer sentido para o entendimento da estrutura econômica mundial e o respectivo sistema de poder a ela subjacente, sustentáculos do que Furtado (2000b) denomina de capitalismo global. Daí também a importância de recuperá-las, contextualizando-as no cenário do mundo globalizado, sob pena de que os países periféricos sejam meras unidades operacionais. Ou, que a dimensão global só lhes atinja no sentido da dissipação de suas identidades, tornando-os homogêneos, em milhares de lugares-globais, entidades amorfas, mantidas sempre à margem das decisões que, emanadas do centro, determinam as condições de sobrevivência de todos.

Por isso também a relevância de se resgatar a noção geográfica de território, pois é esta a base concreta e objetiva dos lugares e se constitui "pelo conjunto indissociável do substrato físico, natural ou artificial, (...), ou (...) a base técnica e mais as práticas sociais, isto é, uma combinação de técnica e de política" (SANTOS, 2002a, p. 87). Está, portanto, ligado à idéia de domínio e gestão de uma determinada área. Dessa forma, "devese ligar sempre a idéia de território à idéia de poder, quer se faça referência ao poder público, estatal, quer ao poder das grandes empresas que estendem os seus tentáculos por grandes áreas territoriais, ignorando as fronteiras políticas" (ANDRADE, 1998, p. 213).

O território é, então, o palco de conflitos de interesses que, no contexto da globalização, materializam, nos lugares, o confronto entre o espaço local, aquele "vivido por todos os vizinhos" e o espaço global, "habitado por um processo racionalizador e um conteúdo ideológico de origem distante e que chegam a cada lugar com os objetos e as normas estabelecidos para servi-los" (SANTOS, 1998, p. 18). 
A partir dessa dialética Santos (1997, 1998, 2002a) identificou novos recortes no território aos quais chamou de horizontalidades e verticalidades. E assim os explicitou: "as horizontalidades serão os domínios da contigüidade, daqueles lugares vizinhos reunidos por uma continuidade territorial, enquanto as verticalidades seriam formadas por pontos distantes uns dos outros, ligados por todas as formas e processos sociais" (SANTOS, 1998, p. 16).

As forças que conduzem o processo de horizontalização são centrípetas, isto é, são forças de agregação e fatores de convergência em relação a uma base territorial específica; as que conduzem a verticalização são centrífugas, ou seja, são forças de fragmentação e fatores de desagregação dessa mesma base (SANTOS, 1997).

Para Santos (1998, p. 16) as redes justificam, de certa maneira, a expressão verticalidade, porque dispensam continuidades e contigüidades, embora não as excluam, e adverte: "além das redes, antes das redes, apesar das redes, depois das redes, com as redes, há o espaço banal, o espaço de todos, todo o espaço, porque as redes constituem apenas uma parte do espaço e o espaço de alguns" (SANTOS, 1998, p. 16).

Longe de desestimular as análises que se fazem nos estudos organizacionais, essa advertência pode contribuir para ampliar a compreensão dos fenômenos e das formas interorganizacionais estudadas, ou, para posicionálas, uma vez que traz também a possibilidade de qualificar os vetores das ações reticulares vistas como promotoras de desenvolvimento de um determinado território. Porque são os mesmos lugares que conformam as redes e o espaço banal, há uma sobreposição dos recortes horizontais e verticais que permitem delinear os vetores das ações organizacionais, impulsionados por forças centrípetas e centrífugas que atravessam o território e, portanto, as redes.

Governado por forças centrífugas, o território e as redes aí constituídas engendram, de fato, verticalidades ou, "vetores de uma racionalidade superior e do discurso pragmático dos setores hegemônicos, criando um cotidiano obediente e disciplinado". As forças centrípetas, por sua vez, engendram horizontalidades. Mas estas são "tanto o lugar da finalidade imposta de fora, de longe e de cima, quanto o da contrafinalidade, localmente gerada. Elas são o teatro de um cotidiano conforme, mas não obrigatoriamente conformista e, simultaneamente, o lugar da cegueira e da descoberta, da complacência e da revolta" (SANTOS, 1997, p. 227). Porque sobre as forças centrípetas agem forças centrífugas, que advêm de escalas mais amplas. Assim, a agregação e a convergência, providas pelas forças centrípetas, são permanentemente perturbadas pelas forças centrífugas.

$\mathrm{Na}$ atualidade, a tendência é de ampliação das verticalidades, tanto no plano virtual como no plano real. A fluidez informacional produzida pelas novas tecnologias de informação e comunicação garante sustentação às verticalidades virtuais. A disponibilização de créditos internacionais aos países e regiões mais pobres, direcionados ao estabelecimento de segmentos produtivos concretiza a funcionalidade dos lugares e das redes ao grande capital.

Mas também os lugares e os agentes locais podem fortalecer as horizontalidades, "reconstruindo, a partir das ações localmente constituídas, uma base de vida que amplie a coesão da sociedade civil, a serviço do interesse coletivo" (SANTOS, 1997, p. 227). A sobreposição dos recortes e a simultaneidade das forças criam, na visão de Santos (1998, p. 16) "novas solidariedades", a despeito de diferenças entre pessoas ou lugares.

As "novas solidariedades" têm, como elemento central, a informação que adquiriu, ao longo do tempo, a capacidade de reunir diferentes porções de um território. Para o autor supracitado, as "novas solidariedades" podem ocorrer sob três diferentes formas: homóloga, complementar ou hierárquica. A homologia diz respeito às áreas de produção modernizadas e confluentes em função de uma informação especializada que, presidindo a racionalidade, cria similitude de atividades e gera contigüidades funcionais. A complementaridade se refere à articulação entre diferentes atividades, que se estabelecem igualmente em decorrência da modernização produtiva e da necessidade de intercâmbio geograficamente próximo. A forma hierárquica, como resultado da crescente racionalização das atividades, ocorre sob comando tendencialmente concentrado em um agente, ou uma organização que, independentemente de sua localização, interfere no espaço sócio-territorial. 
Sob as duas primeiras formas, o sentido, o cotidiano é compartido mediante regras estabelecidas ou reformuladas localmente. Nesse caso, a informação tende a se generalizar, ou seja, tende ao domínio coletivo local. Sob forma hierárquica, se estabelece um cotidiano imposto externamente, comandado por informação privilegiada, secreta e que se caracteriza como importante recurso de poder (SANTOS, 1998).

Assim, as formas homólogas ou complementares podem induzir transformações sociais direcionadas à homogeneização social que "não se refere à uniformização dos padrões de vida, e sim a que membros de uma sociedade satisfazem de forma apropriada as necessidades de alimentação, vestuário, moradia, acesso à educação, ao lazer e a um mínimo de bens culturais" (FURTADO, 1992, p. 6). Já a forma hierárquica se restringe a modernizar o estilo de vida de segmentos da população, ou seja, aquelas capazes de consumir a última técnica, a última moda. Se privilegiadas na formulação das políticas voltadas para o desenvolvimento, ainda que dito local, aprofundam a heterogeneidade social no território.

A homogeneização social tem, então, caráter demarcatório na caracterização da dicotomia desenvolvimentosubdesenvolvimento pois, como continua Furtado (1992, p. 6-7): "as teorias do desenvolvimento são esquemas explicativos dos processos sociais em que a assimilação de novas técnicas e o consequiente aumento de produtividade conduzem à melhoria do bem-estar de uma população [...]". Já "a teoria do subdesenvolvimento cuida do caso especial de processos sociais em que aumentos de produtividade e assimilação de novas técnicas não conduzem à homogeneização social".

Profundamente vinculado ao modo de inserção na divisão internacional do trabalho, fruto da assimilação indireta do capitalismo industrial, o subdesenvolvimento é a expressão maior da relação de dependência instituída entre países centrais e periféricos. Contudo, a teorização de Furtado não é paralisante, pois

o fato de que as estruturas que [...] conformam [o subdesenvolvimento] se hajam reproduzido no decorrer de decênios não nos autoriza a prever sua permanência futura. Mas podemos afirmar que a tendência dominante é no sentido de sua reprodução. Nesse caso, a teoria explicativa capacita os agentes sociais pertinentes a escapar do fatalismo da chamada necessidade histórica (FURTADO, 1992, p. 12).

As "novas solidariedades" tipificadas por Santos (1998) são expressões de formas sociais, engendradas pelo jogo político que ocorre no território, mas que não se confina a ele. Tampouco as ações empreendidas por essas novas formas sociais podem se restringir ao resgate e ao fortalecimento das vocações locais, sob pena de refazer o percurso das vantagens comparativas, modo de assimilação indireta da civilização industrial, cujo resultado não é outro senão que a perpetuação da estrutura centro-periferia.

Assim, a exploração de elementos teórico-empíricos formulados por Celso Furtado e Milton Santos oferece alternativa instigante para o entendimento e o aporte de conteúdo praxiológico ao construto desenvolvimento local, posicionado no contexto da globalização. Recortes territoriais (horizontalidades-verticalidades), direção dos movimentos de força (centrípeta-centrífuga) e formas de articulação (homologia, complementaridade e hierarquia) são categorias que permitem o entendimento das bases de formação e sustentação de articulações interorganizacionais, genericamente classificadas como redes e operacionalizadas em parcerias, consórcios, arranjos produtivos, alianças, clusters. Homogeneidade ou heterogeneidade social engendradas, ou fortalecidas, pela ação de tais articulações desvelam seu alcance e seu potencial transformador, no âmbito do espaço territorial vivenciado pelas pessoas que são, ao final, seu alvo.

Na seqüência, é apresentada parte de um trabalho empírico realizado em 2005, que despertou o interesse em buscar alternativas de compreensão e, ao final, algumas inquietações surgidas e implicações para os estudos organizacionais. 


\section{0 pólo de tecnologia de informação e comunicação como vetor de desenvolvimento do Estado de Pernambuco}

Os dados apresentados nesta seção foram obtidos em trabalho investigativo mais amplo que incluiu cinco estados da Região Nordeste do Brasil, onde estão localizados seis programas de pós-graduação em Ciência da Computação, recomendados pela Coordenação de Aperfeiçoamento de Pessoal de Nível Superior (CAPES). Tendo como estratégia de pesquisa o estudo comparativo de casos, aquele trabalho procurou descrever e analisar o modo pelo qual a articulação entre o contexto institucional de referência da produção científica e tecnológica e as formas de inserção das universidades na localidade interfere no desenvolvimento local (GOULART, 2005).

Sob abordagem qualitativa, escolheu-se, intencionalmente, estudar o campo da Ciência da Computação. Primeiramente porque as pesquisas realizadas nessa área caracterizam-se por forte conteúdo científico e tecnológico, sendo quase impossível delimitar onde termina a preocupação em fazer ciência, no sentido de pesquisas de natureza teórica, que busca as explicações mais gerais dos fenômenos; ou básica, que estuda as características, componentes ou distribuição de determinados fenômenos; ou ainda aplicadas, voltadas para soluções de problemas, geração de inovações, processos e produtos.

Evidentemente, a Ciência da Computação não é a única área assim caracterizada. Em tese, diversas outras áreas poderiam constituir o caso. Mas, houve outro determinante nessa escolha, qual seja a centralidade da tecnologia da informação como motor da dinâmica sócio-econômica no contexto da globalização e sua transversalidade, devido ao encadeamento de seus efeitos para todos os setores do universo social. Nesse sentido, a área é potencialmente fomentadora do que Hirschman (1977 apud EVANS, 2004, p. 32) chamou de "conspiração multidimensional' a favor do desenvolvimento".

Peter Evans, um dos grandes estudiosos do setor de tecnologia da informação, inclusive da indústria de computadores no Brasil, afirma que esse "é o setor com mais probabilidade de catalisar uma conspiração a favor do desenvolvimento no século XXI" (EVANS, 2004, p. 36).

A Ciência da Computação é um dos eixos centrais desse setor que é cada dia mais encarado como uma "janela de oportunidade" para uma grande variedade de agentes, desmistificando o imperativo estrutural da divisão internacional do trabalho e sua teoria de vantagens comparativas. Furtado (1978, p.103) já adiantava: "a luta contra a dependência passa [...] por um esforço para modificar a conformação global do sistema".

Com efeito, tanto os trabalhos do Grupo de Trabalho Interministerial para a Recriação da SUDENE como outros importantes documentos acerca da questão regional tem colocado a criação e/ou fortalecimento de sistemas locais de inovação ou ambientes de inovação como propulsores de transformações sociais. Referidos à articulação de agentes e instituições capazes de mobilizar projetos coletivos de inclusão social, cultural, política e econômica da população, tais documentos invariavelmente incluem a incorporação do conhecimento científico e tecnológico ao processo produtivo, como se pode ver em Coutinho (2004); Marinho (2000) e Melo (2003), por exemplo.

Nos trabalhos de Coutinho (2004) e Melo (2003) o setor de tecnologia da informação foi elencado entre as alternativas mais promissoras da Região Nordeste, tendo em vista a existência de recursos humanos qualificados e unidades de pesquisas nas Universidades; Marinho (2000) explorou particularmente o setor de software, concentrando-se na caracterização das empresas nordestinas da área, em sua articulação com os sistemas locais de inovação e na proposição de políticas para a formação de redes de empresas.

De fato, o setor de software desempenha papel central no novo paradigma tecno-econômico, dotado de forte potencial inovador, particularmente no cenário de convergência das tecnologias de informação (BRASIL, 2005a; VASCONCELOS, 2005). Indo mais além, Araújo e Meira (2005, p. 1) consideram que a indústria de software é "protagonista de um conjunto de mudanças tecnológicas [...]" e "importante elemento propulsor de desenvolvimento econômico e social”. Em geral, essa indústria se caracteriza pela predominância de pequenas 
empresas e pode ser desenvolvida "em qualquer região que possua os pré-requisitos básicos de um sistema de inovação e é uma grande geradora de empregos qualificados".

Neste artigo, é apresentada a parcela de dados coletados em fontes primárias e secundárias, referentes à origem e à constituição do pólo de tecnologia de informação e comunicação no Estado de Pernambuco, fruto de iniciativas mobilizadas pela comunidade acadêmico-científica, pelos Governos Estadual e Municipal, empresas privadas nacionais e estrangeiras e organizações sociais. A origem dessas iniciativas é creditada aos professores e pesquisadores do Centro de Informática da Universidade Federal de Pernambuco (CIn/UFPE) que, desde o início da década de 1990, vêm desenvolvendo ações no sentido de articular a busca de excelência na formação, na qualificação e na produção científica realizada na Universidade com formas produtivas de inserção local.

Entre as primeiras ações que deram impulso ao pólo estão a criação do Centro de Tecnologia de Software para Exportação (Softex Recife), agente local do Programa Nacional de Software para Exportação (Softex 2000), iniciado pelo Conselho Nacional de Desenvolvimento Científico e Tecnológico (CNPq) em 1993 e a implantação do Projeto Gênesis que, no âmbito do mesmo Programa, tem o objetivo de fomentar a criação de empreendimentos em software e tecnologias de informação. A partir do Projeto Gênesis, o CIn criou o RecifeBEAT (Base para Empreendimentos de Alta Tecnologia) voltada para a geração de empreendedores ainda em fase de formação no nível de graduação.

O Softex Recife foi criado em 1994 e seu conselho deliberativo é formado pela UFPE, pela Associação de Empresas de Processamento de Dados (ASSESPRO), pela Sociedade dos Usuários de Computadores e Equipamentos Subsidiários (SUCESU), ambas da seção Pernambuco, pelo Governo do Estado, pela Prefeitura do Recife, pela Federação de Indústria de Pernambuco e por uma representação das empresas associadas. Conta, atualmente com cerca de 50 empresas associadas, na maioria de pequeno porte, todas com projetos de desenvolvimento de software para exportação (CENTRO DE TECNOLOGIA DE SOFTWARE PARA EXPORTAÇÃO DO RECIFE, 2005). A incubação de empresas recebe suporte do Projeto Gênesis, via RecifeBEAT, atualmente coordenado em parceria com o Centro de Estudos e Sistemas Avançados do Recife (C.E.S.A.R.); este, mais uma das iniciativas de professores e pesquisadores vinculados à UFPE.

A criação do C.E.S.A.R, uma associação civil de direito privado, sem fins lucrativos, foi fruto do sucesso daquelas outras iniciativas bem como do reconhecimento da qualidade dos cursos de graduação e pósgraduação oferecidos pelo CIn/UFPE. A principal motivação para a criação do C.E.S.A.R foi a percepção de que, desde o início da década de 90, a reconhecida qualificação dos profissionais formados pelo CIn o estava transformando em uma "casa de passagem", uma vez que os egressos não encontravam em Pernambuco, ou na região, oportunidades de trabalho ou ambientes favoráveis à criação de empresas de tecnologia de informação (CENTRO DE ESTUDOS E SISTEMAS AVANÇADOS DO RECIFE, 2005b).

Com esta motivação, o C.E.S.A.R definiu, como seu objeto, "o ensino, a pesquisa, o treinamento, o desenvolvimento e consultoria, a representação e exportação de serviços e produtos no campo da tecnologia da informação" (CENTRO DE ESTUDOS E SISTEMAS AVANÇADOS DO RECIFE, [1996], p. 1). O objetivo principal, declarado no Estatuto, é o avanço científico e tecnológico do CIn e da Ciência da Computação no País, a modernização e o aumento da competitividade industrial do Estado de Pernambuco e do Brasil.

Para alcançar tais objetivos, o C.E.S.A.R mantém intensa relação com o CIn, mediante a contratação prioritária de seus recursos humanos e instalações. Por meio de convênios, realiza repasse de recursos para financiamento das atividades de P\&D ou infra-estrutura de pessoal adicional ao CIn ou para complementação do seu quadro de bolsas. Segundo um de seus fundadores e atual cientista-chefe, em entrevista, houve períodos em que para cada real de custeio provido pelo Governo Federal ao CIn, o C.E.S.A.R aportou dez (MEIRA, entrevista, 2005).

Atuando como um instituto de inovação, incubadora de empresas e fábrica de software, o C.E.S.A.R representa uma efetiva inserção local do CIn/UFPE, que avançou para uma intervenção no setor econômico do Estado de Pernambuco, contribuindo para a criação de mais de 30 empreendimentos no setor de tecnologia da informação. Juntamente com o Softex Recife teve importante papel na construção de um ambiente favorável à 
criação do pólo de tecnologia da informação do Estado de Pernambuco. A própria idéia de criação do Porto Digital, como organismo estruturante do arranjo produtivo local de tecnologia de informação e comunicação, foi gestada no âmbito daquelas duas organizações.

Criado em 2000, mediante o aporte de recursos públicos estaduais, o Porto Digital é gerido por um Núcleo, definido como uma associação civil sem fins lucrativos, qualificado como organização social. A Secretaria de Ciência, Tecnologia e Meio Ambiente do Estado (SECTMA), o C.E.S.A.R, o CIn e o Softex Recife são suas âncoras nos aspectos de liderança, definição e execução de políticas setoriais, excelência na produção e concepção de idéias fundamentais para o ecossistema (PORTO DIGITAL, 2005). Entre seus números mais expressivos estão a reunião de 90 organizações e a geração de 2,5 mil postos de trabalho. Para fomentar a criação de empreendimentos, conta com duas incubadoras associadas: a C.A.I.S do Porto e o próprio C.E.S.A.R que atua também como incubador de empresas de tecnologia de informação.

O cluster coordenado pelo Porto Digital compreende, além de pequenas e micro-empresas criadas localmente, multinacionais como a Sun, a Borland, a Motorola e, recentemente, passou a abrigar um dos três centros de pesquisa da Nokia no Brasil.

Ao mesmo tempo, o C.E.S.A.R se transformou num importante player da indústria nacional de software a ponto de estar se preparando para desmembrar sua fábrica de software da estrutura atual. Com um faturamento de R \$ 30 milhões em 2004, previa chegar a 45 milhões em 2005 (O C.E.S.A.R..., 2005). Com um quadro de 350 colaboradores, instalou escritório de negócios em São Paulo e em Brasília.

Além das ações diretamente voltadas para o mercado, o Porto Digital e o C.E.S.A.R desenvolvem ações no campo das políticas públicas de inclusão digital, atuando nas comunidades vizinhas às suas instalações, que se situam no Bairro do Recife Antigo, numa articulação ao projeto de revitalização do Centro Histórico do Recife. Todas as empresas associadas são estimuladas, mediante instrumentos de renúncia fiscal, a se instalarem nessa mesma área. Dessa forma, essas entidades pretendem aprofundar seus laços com projetos locais de desenvolvimento social.

A importância que o setor de tecnologia da informação adquiriu no cenário sócio-econômico do Estado é demonstrado também pela iniciativa da Agência Estadual de Planejamento e Pesquisas de Pernambuco CONDEPE/FIDEM, em desenvolver indicadores de tecnologia da informação e comunicação (TI\&C) e em realizar o cálculo estimativo do PIB do setor. O objetivo foi conhecer sua dimensão econômica, os impactos dos investimentos públicos e privados e a participação na geração de emprego e renda.

Em 2005 foi publicada a pesquisa realizada em parceria com a Fundação de Amparo à Ciência e Tecnologia do Estado de Pernambuco, na qual o cálculo estimativo do PIB do setor de TI\&C alcançou, em 2003, 3,5\% do PIB total do Estado. Esse setor inclui, entre outros, a telefonia fixa e móvel e a estimativa usou dados de valor adicionado a partir de 1999. Isolando a tecnologia da informação, os pesquisadores concluíram que esta tem uma participação de 29,85\% no PIB de TI\&C, ou 1,04\% do PIB do Estado. Nos anos de 1999 e 2000 houve grande expansão da telefonia celular, o que ampliou a base de cálculo do sub-setor comunicação (PERNAMBUCO, 2005). Não somente pelo impacto dos números, mas pelo interesse em organizar e manipular informações acerca da dinâmica do setor pode-se inferir a relevância que o setor atingiu no âmbito do Estado.

Em face dos objetivos traçados no trabalho investigativo realizado por Goulart (2005), observou-se que, no caso específico de Pernambuco, a produção científica e tecnológica realizada no Programa de Pós-Graduação em Ciência da Computação da UFPE vai além da referenciação ao contexto internacional, ou seja, o Programa ocupa posições no campo científico (BOURDIEU, 1983). Sua inserção local também ficou bastante evidente, vistas as ações empreendidas que resultaram na formatação de modelos interorganizacionais de grande impacto no cenário econômico do Estado. A comparação com os demais casos estudados permitiu inferir que, de fato, a articulação entre a internacionalização na produção científica e tecnológica e a inserção local do Programa, era um diferencial importante. 
Mais do que o atendimento às demandas locais, aquelas ações criaram novas exigências sobre a base produtiva, política e infra-estrutural existentes. No Estado de Pernambuco, o setor de tecnologia da informação ganhou ares de vocação local mas, à diferença de atividades que se baseiam na exploração quase exclusiva dos recursos naturais ou ambientais, como o turismo, por exemplo, foi construída a partir da liderança assumida pelos pesquisadores em ações de intervenção no campo de poder local.

Entretanto, até aqui se ficou quase que exclusivamente no campo econômico e no espaço interorganizacional, ou, no espaço das redes. Tomando-se o volume de recursos financeiros movimentados no âmbito das ações capitaneadas pelo Porto Digital e pelo C.E.S.A.R, expoentes do pólo de tecnologia de informação e comunicação do Estado de Pernambuco, ou o êxito na atração de investimentos para o Estado, ou ainda o número de empresas criadas, parece não haver dúvida de que a formação de tal arranjo produtivo tem impacto na localidade. Porém, estará efetivamente movendo transformações sociais no território, ou estaria ainda no campo da simples modernização de atividades produtivas? Ou caminhando para ser mais um dos lugaresglobais, apropriados pela fragmentação e flexibilização produtivas no cenário da globalização?

Dados apresentados no documento Síntese de Indicadores Sociais (INSTITUTO BRASILEIRO DE GEOGRAFIA E ESTATÍSTICA, 2005) e na Relação Anual de Informações Sociais (RAIS), cujo banco de dados é organizado pelo Ministério do Trabalho e Emprego e financiado pelo Fundo de Amparo ao Trabalhador (BRASIL, 2005b) permitem algumas reflexões iniciais.

Tomando-se o valor do salário mínimo vigente em 2003 ( $\mathrm{R} \$ 240,00)$, viu-se que o rendimento médio mensal dos trabalhadores do estado de Pernambuco se situava na faixa de remuneração que varia de 1,51 a 2,00 salários mínimos. Entre os profissionais de informática, com empregos formais no estado, cerca de $95 \%$ deles encontravam-se acima dessa faixa, segundo dados da RAIS-2003; 53\% obtiveram rendimentos acima de 10 salários mínimos. Todos os profissionais empregados tinham curso superior completo, situação bastante diferente da população de 25 anos ou mais que, em Pernambuco, atingia a média de 5,2 anos de estudos. Num cenário em que a taxa de analfabetismo funcional das pessoas com 15 anos se situa acima de 50\%, percebe-se a necessidade premente da implementação de planos e políticas integradoras, capazes de sustentar e impulsionar o desenvolvimento local a partir de possibilidades criadas e geridas no território, que não se confinem a ele mas também não o instrumentalizem como mera unidade operacional.

\section{As inquietações, as implicações...}

Se há dados promissores quanto à qualificação dos empregos criados e à rentabilidade dos negócios no setor de tecnologia de informação e comunicação e do potencial do arranjo produzido pela articulação de diferentes agentes, há também questionamentos acerca da amplitude das ações, da lógica orientadora, das forças que as governam e do sentido dos recortes que marcam o território.

Ao buscar os elementos teórico-empíricos formulados por Celso Furtado e Milton Santos, percebe-se a necessidade de ampliar e posicionar a análise; de olhar o território e as transformações sociais efetivamente ocorridas ou que estão a ocorrer; de extrapolar o universo das organizações, e das redes, e provocar reflexões acerca dos efeitos dessas ações sobre a estrutura social e o "espaço banal".

Assim, levantam-se algumas implicações e possibilidades para as pesquisas no campo dos estudos organizacionais que se debruçam sobre a questão do desenvolvimento local. Uma delas é a necessidade de assumir o caráter específico do processo de desenvolvimento dos países periféricos, ou melhor, de assumir a condição e as peculiaridades do subdesenvolvimento. Assumir não é se conformar, naturalizar. É, como se vê no Aurélio, "tomar sobre si ou para si; avocar" ou "chamar a si, assumir a responsabilidade de" (FERREIRA, 1994-1995, p. 68). Ou seja, é necessário posicionar-se pois, como advertiu Furtado (1992, p. 19),

o subdesenvolvimento, como o deus Janus, tanto olha para a frente como para trás, não tem orientação definida. É um impasse histórico que espontaneamente não pode levar senão a alguma 
forma de catástrofe social. Somente um projeto político apoiado em conhecimento consistente da realidade social poderá romper a sua lógica perversa.

A ampliação do nível de análise é, assim, uma das principais implicações para os estudos organizacionais. Enquanto estivermos presos às unidades de análise, ainda que sejam redes, estaremos olhando somente para "uma parte do espaço e o espaço de alguns" (SANTOS, 1998, p. 16). Ainda que possamos produzir estudos importantes sobre os híbridos constituídos pela articulação de diferentes agentes, restringir a análise ao nível organizacional ou interorganizacional ao abordar a questão do desenvolvimento local é limitante e pouco poderá falar das implicações de tais configurações para a vida no território.

Ao mesmo tempo, as categorias buscadas em Milton Santos possibilitam ampliar o nível de análise sem nos afastar do objeto privilegiado nos estudos organizacionais - as organizações e suas múltiplas interações e formas. A partir delas e agregando-se as formas de articulação, a direção dos movimentos de força e os recortes verticais e horizontais no território e nas redes, é possível ampliar a análise e buscar compreensão de suas implicações no mundo da vida, nas externalidades geradas no e para o coletivo.

Tomando-se por base o cluster de tecnologia de informação e comunicação estruturado pelo Porto Digital pode-se formular um breve exercício de análise, à luz das categorias buscadas em Milton Santos, sugestivo para futuros aprofundamentos e carente de maiores discussões acerca de sua pertinência epistemológica e metodológica.

Como se viu na seção anterior, o cluster de tecnologia de informação e comunicação de Pernambuco se configurou, desde sua origem, pela articulação de diferentes agentes do Estado, do mercado e da sociedade. Assim como é certo que nasceu de iniciativas de agentes locais, é certo também que rapidamente atraiu agentes externos, nomeadamente, grandes empresas transnacionais. Se criou novas demandas sobre o território, pode criar também novas clivagens.

Nesse sentido, a identificação dos recortes verticais e/ou horizontais pode ser explorada como indicativo do que efetivamente ocorre no território. Como se viu em Santos (1998), as horizontalidades são engendradas por forças centrípetas, em articulações homólogas ou complementares, ou seja, que conjugam ações e atividades que atravessam o território, que se espraiam por ele. As verticalidades representam o domínio de forças centrífugas, que se apropriam da informação (e dos recursos), em direção a um cotidiano externo, em fluxo hierárquico, isto é, sob um comando, concentrador de ações e atividades no núcleo do negócio. Nesse desenho, as ações não percorrem o território, mas passam por uma pequena parcela dele e para este núcleo atraem todas as forças. Segundo Santos (1998, p. 17) "há [...] um centripetismo [...], mas é um centripetismo do outro".

A adoção dessas categorias parece bastante apropriada para análise especialmente nos casos em que as redes criadas, ou analisadas, confluem para atividades mercantis, de forte atração ao capital privado, inclusive internacional. Nesses casos, o negócio criado pela articulação pode tornar-se um fim em si mesmo, cooptando os demais agentes para a sua lógica. Se assim ocorre, as relações inteorganizacionais passam a ser movidas pelos imperativos do mercado e o território torna-se um mero suporte das operações. Os agentes locais, particularmente o Estado, sempre presente nessas articulações, podem se "embriagar" com o sucesso financeiro e comercial do negócio e terminar priorizando seus investimentos em direção a ele, em prejuízo de suas responsabilidades essenciais.

Esse questionamento não desvaloriza iniciativas inovadoras, simplesmente pelo apelo mercantil que adquirem, como no caso do pólo de tecnologia de informação e comunicação de Pernambuco; mas quer buscar, nelas, a força de transformação social. Não é demais repetir a citação de Manuel Correia de Andrade, outro grande pensador brasileiro das questões regionais, de que "deve-se ligar sempre a idéia de território à idéia de poder" (ANDRADE, 1998, p. 213). Assim, mesmo que a ação política seja orientada

para um interesse particular e específico [...] este é, apenas, um primeiro momento. As atividades que, complementares ou não, têm uma lógica diversa da atividade dominante, provocam, a partir do seu conflito de preocupações, um debate que acaba por interessar ao conjunto da sociedade local. E o 
resultado é a busca de um sistema de reivindicações mais abrangentes, adaptado às contingências da existência comum, no espaço da horizontalidade (SANTOS, 1998, p. 228-229).

No dizer de Furtado (2002, p. 63 e 32-33) "na vida social nada é mais indicativo de canalização de forças criadoras para os fins do que a existência de atividade política" e esta, sendo essencial ao desenvolvimento "se manifesta quando à percepção dos obstáculos a superar, adiciona-se um forte ingrediente de vontade coletiva". Num território marcado pela heterogeneidade social, onde sempre predominaram atividades produtivas tradicionais, como a monocultura da cana, por exemplo, esse pode ser um dos principais efeitos da constituição do pólo de tecnologia de informação e comunicação em Pernambuco

Finalmente, é preciso enfatizar que o breve espaço de um artigo certamente não é suficiente para explorar a riqueza do pensamento e da obra de Celso Furtado e Milton Santos mas, como inspiração, conduz a novas dúvidas, essenciais para a ampliação do esforço de compreensão da realidade social em que estamos inseridos e para a qual cabe nossa contribuição. 


\section{Referências}

ANDRADE, Manuel Correia de. Territorialidades, desterritorialidades, novas territorialidades: os limites do poder nacional e do poder local. In: SANTOS, Milton; SOUZA, Maria Adélia A. de; SILVEIRA, Maria Laura (Orgs.). Território: globalização e fragmentação. 4. ed. São Paulo: Hucitec: ANPUR, 1998. p. 213-220.

ARAÚj0, Eratóstenes Edson Ramalho de; MERA, Slivio Romero de Lemos Inserção compeitiva do Brasil no mercado intemacional de software. [S]], 2005. Disponível em: বtttp://wwwsoftexbr/media/nsercao-competitiva-do-Brasil-no-mercado-intemacional-de softwarepdf $>$. Acessoem 20 set. 2005.

BOURDIEU, Pierre. 0 campo científico. In: . Pierre Bourdieu: sociologia. São Paulo: Ática, 1983. Cap. 4, p. 122-155. Organizador: Renato Ortiz.

BRASIL. Ministério da Ciência e Tecnologia. Política Nacional de Informática. Brasília, 2005a. Disponível em: <http://www.mct.gov.br/inclusao/index.htm>. Acesso em 20 set. 2005.

Ministério do Trabalho e Emprego. Bases estatísticas RAIS/CAGED: acesso on-line. Brasília, 2005b. Disponível em: <https//sgt.caged.com.br/index.htm>. Acesso em 10 abr. 2005.

BRUNDTLAND, G. H. (coord.). Nosso futuro comum. 11. ed. Rio de Janeiro : FGV, 1991.

CENTRO DE ESTUDOS E SISTEMAS AVANÇADOS DO RECIFE. Estatuto social. Recife, [1996]. Disponível em: <http://imprensa.cesar.org.br/estatutos.pdf>. Aceso em 10 maio 2005.

. Empresa: ecossistema. Recife, 2005b. Disponível em: <http//www.cesar.org.br>. Acesso em 10 mar. 2006.

História do C.E.S.A.R. Recife, 2005b. Disponível em: <http//www.cesar.org.br>. Acesso em 10 mar. 2005.

CENTRO DE TECNOLOGIA DE SOFTWARE PARA EXPORTAÇÃO DO RECIFE. Histórico. Recife, 2005. Disponível em: $<$ http://www.recife.softex.br>. Acesso em 10 set. 2005.

O C.E.S.A.R se desgarra e vai conquistar o mundo. O Estado de São Paulo. São Paulo, 15 maio 2005. Economia. Disponível em: <http://txt.estado.com.br/editoriais/2005/05/15/eco028.html>. Acesso em 17 maio 2005.

COUTNHO, Luciano (Coord.). A inserção competitiva do Nordeste: proposta para a contribuição da ciência e tecnologia. Fortaleza: Banco do Nordeste do Brasil, 2004.

EVANS, Peter. Autonomia e parceria: estados e transformação industrial. Rio de Janeiro: Ed. UFRJ, 2004.

FERREIRA, Aurélio Buarque de Holanda. Dicionário Aurélio básico da língua portuguesa. São Paulo: Folha de S. Paulo; Rio de Janeiro: Nova Fronteira, 1994- 1995.

FURTADO, Celso. 0 capitalismo global. 4. ed. São Paulo: Paz e Terra, 2000a.

FURTADO, Celso. Criatividade e dependência na civilização industrial. São Paulo: Círculo do Livro, 1978.

. Em busca de novo modelo: reflexões sobre a crise contemporânea. 2. ed. São Paulo: Paz e Terra, 2002.

Introdução ao desenvolvimento: enfoque histórico-estrutural. 3. ed. rev. São Paulo: Paz e Terra, 2000a.

O mito do desenvolvimento econômico. Rio de Janeiro: Paz e Terra, 1974.

O subdesenvolvimento revisitado. Economia e Sociedade, Campinas, n. 1, p. 5-19, ago. 1992.

GLOBALIZAÇÃO aumenta desigualdade, diz ONU. Folha de São Paulo, São Paulo, p. B1, 25 fev. 2004.

GOULART, Sueli. Sobre a interferência da produção científica e tecnológica da universidade no desenvolvimento local: 0 caso da Ciência da Computação. 2005. Tese (Doutorado em Administração) - Universidade Federal de Pernambuco, Recife, 2005.

GOULART, Sueli; VIEIRA, Marcelo Milano Falcão; CARVALHO, Cristina Amélia. Universidades e desenvolvimento local: uma abordagem institucional. Porto Alegre: Sagra Luzzatto, 2005. 
GUAN, Jiancheng; MA, Nan. A comparative study of research performance in computer science. Scientometrics, V. 61, n. 3,p. 339-359, 2004.

IANNI, Octavio. Metáforas da globalização. In: Teorias da globalização. 10. ed. Rio de Janeiro: Civilização Brasileira, 2002. Cap. 1, p. 11-25.

INSTITUTO BRASILEIRO DE GEOGRAFIA E ESTATÍSTICA (IBGE). Síntese de indicadores sociais: 2004. Rio de Janeiro, 2005. (Estudos e Pesquisas. Informação Demográfica e Socioeconômica; n. 15).

MARINHO, Cláudio. 0 setor de software no Nordeste: oportunidades de inovação competitiva. Fortaleza: Banco do Nordeste, 2000.

MEIRA, Sílvio. Entrevista concedida a Sueli Goulart. Recife, maio 2005.

MELO, Lúcia C. P. de. A função ciência, tecnologia e inovação (CT\&I) na nova agenda de desenvolvimento para o Nordeste. [Recife], jun. 2003.

OLIVO, Vânia Maria Fighera; MISOCZKY, Maria Ceci. As estratégias discursivas presentes na origem do referencial para o desenvolvimento sustentável: uma análise crítica do Relatório de Brundtland. In: ENCONTRO ANUAL DA ASSOCIAÇÃO NACIONAL DOS PROGRAMAS DE PÓS-GRADUAÇÃO EM ADMINISTRAÇÃO, 27., 2003, Atibaia. Anais... [Rio de Janeiro]: ANPAD, 2003. 1 CD-ROM. Área e número: POP 1757.

PERNAM BUCO. Agência Estadual de Planejamento e Pesquisa de Pernambuco - CONDEPE/FIDEM. Tecnologia da informação e comunicação do Estado de Pernambuco: pesquisa ITC/PE-2003; estimativa do PIB - 2003. Recife, 2005.

PORTO DIGITAL. Institucional. Recife, 2005. Disponível em: <http://www.portodigital.org.br>. Acesso em 20 set. 2005.

SACHS, Ignacy. Pensando sobre o desenvolvimento na era do meio ambiente : do aproveitamento racional da natureza para a boa sociedade. In: . Caminhos para o desenvolvimento sustentável. Rio de Janeiro : Garamond, 2000. Cap. 2, p. 47-64.

SANTOS, Milton. A natureza do espaço: técnica e tempo, razão e emoção. 2. ed. São Paulo: Hucitec, 1997.

O país distorcido: o Brasil, a globalização e a cidadania. São Paulo: Publifolha, 2002a.

Por uma outra globalização: do pensamento único à consciência universal. 9. ed. Rio de Janeiro: Record, 2002.

0 retorno do território. In: SANTOS, Milton; SOUZA, Maria Adélia A. de; SILVEIRA, Maria Laura (Orgs.). Território: globalização e fragmentação. 4. ed. São Paulo: Hucitec: ANPUR, 1998. p. 15-20.

SIDDHARTAN, N. S. 0 impacto da tecnologia da informação na Índia. 2005. Palestra proferida no Seminário "Dinâmica do capitalismo no pós guerra fria: cultura tecnológica, espaço e desenvolvimento", Recife, 29 a 31 ago. 2005. Mesa 4: Progresso técnico e a "Nova Dependência".

SUNKEL, Osvaldo. A sustentabilidade do desenvolvimento atual na América Latina. In: ARBIX, Glauco; ZILBOVICIUS, Mauro; ABRAMOVAY, Ricardo (Org.). Razões e ficções do desenvolvimento. São Paulo: Ed. UNESP: EDUSP, 2001. Cap. 13, p. 267- 309.

TENÓRIO, Fernando Guilherme; DUTRA, J osé Luís de Abreu; MAGALHÃES, Carla Marisa Rebelo de. Gestão social e desenvolvimento local: uma perspectiva a partir da cidadania deliberativa. In: ENCONTRO ANUAL DA ASSOCIAÇÃO NACIONAL DOS PROGRAMAS DE PÓSGRADUAÇÃO EM ADM INISTRAÇÃO, 28., 2004, Curitiba. Anais... [Rio de Janeiro]: ANPAD, 2004. 1 CD- ROM. Área e número: GSA-2042.

VASCONCELOS, Lia. O difícil caminho para o mundo. Desafios do desenvolvimento: revista mensal de informações e debate do IPEA e do PNUD, n. 15, out. 2005. Disponível em: <http://www.desafios.org.br>. Acesso em 15 out. 2005.

VIEIRA, Eurípedes Falcão; VIEIRA, Marcelo Milano Falcão. Espaços econômicos: geoestratégia, poder e gestão do território. Porto Alegre: Ed. Sagra Luzzato, 2003.

\footnotetext{
${ }^{1}$ Núcleo de Estudos sobre o Poder e Organizações Locais (NEPOL), da Escola de Administração da UFBA; Programa Gestão Pública e Cidadania, da EASP/FGV; e Polis: Instituto de Estudos, Formação e Assessoria em Políticas Sociais, por exemplo.
} 